\title{
THE S-LAB'S WASH+E SYSTEM: TEN SUSTAINABLE INTERVENTIONS FOR VERNACULAR RURAL HOUSEHOLDS IN DEVELOPING COMMUNITIES
}

\author{
STEPHEN MECCA, LIAM REILLY, CLAIRE KLEINSCHMIDT, JACK RICCI, NAZELLI ACOSTA, \\ ALLISON HERRING, MICHAEL CUDAK, ANDREW DEPERRO, JAMES CUNNINGHAM, \\ BRIDGET MCFADDEN \& CONOR BARRETT \\ S-Lab, Department of Engineering-Physics-Systems, Providence College, USA
}

\begin{abstract}
The GSAP Microflush toilet system, a locally sourced fabricated toilet that features a macro-organismenhanced aerobic filter-digester and an innovative valve that flushes on just $150 \mathrm{cc}$ of water has proven to be an effective sustainable sanitation solution for developing world tropical communities. When coupled with 9 low-cost WASH and energy interventions, the resulting WASH+E system can add health, wellness and other value to a basic rural household. This paper describes each of the interventions including the components, options and costs. Lab prototypes are shown with early results from application deployments in Ghana, Haiti and Nicaragua. GSAP expects the technology to go to scale in multiple models including an extension of its toilet MAKER model, DIY contributions from recipient households and community cooperatives, especially co-ops involving women.

Keywords: rural WASH, sustainable systems, repurposed materials, sanitation, toilets, off-grid, closed systems, potable water, recycling nutrients, water reuse, vernacular architecture.
\end{abstract}

\section{INTRODUCTION}

Motivated by the ongoing success of the (Global Sustainable Aid Project) GSAP Microflush toilet [1] and GSAP's MAKER-LENDER models [2], the S-Lab undertook the project reported here to develop companion off-grid low cost effective WASH and Energy systems that together would add to the quality of life for rural households in developing communities. Under a Grand Challenges Explorations Award from the Bill \& Melinda Gates Foundation, GSAP (in Ghana known as the Ghana Sustainable Aid Project) successfully prototyped a marriage of two technologies: a filter-digester and the Microflush valve. The valve, which was designed in the S-Lab in the Department of Engineering-Physics-Systems at Providence College flushes on as little as $150 \mathrm{cc}$ of reused water from the previous user's hand washing and results in an isolation of waste from human contact, eliminating odors and diseasebearing flies. GSAP has incorporated the valve into multiple designs including a generic macro-organism enhanced aerobic digester. The resulting GSAP Microflush (GMF) system has been designed in a model that is fabricated using local skills and local materials. GSAP has trained and empowered local artisans as toilet MAKERs so far in 18 countries around the world. The entrepreneurial model is effecting reliable off-grid odor-free fly-free sanitation for thousands of households while creating sustainable enterprises for the MAKERs.

In 2015 beginning in Haiti, the authors began a study of households provided to families through a combination of donor funds and recipient efforts. In Haiti, the Haitian Health Foundation has created the Happy House, a small 3-room structure made with rubble, some purchased items and locally harvested materials (wood and sand); in Nicaragua, a slightly simpler structure, known as the Home Build, has been implemented by the North Country Mission of Hope under a donor + recipient model similar to the Happy House. Going forward, both have indicated that the GSAP Microflush toilet will become part of the next generation of Happy Houses and Home Builds. This raised the authors' interest in other synergistic 
WASH interventions plus the possibility of a low-cost lighting and charging system. The next generation has been appropriately termed the 'Happier Houses'.

\section{THE WASH+E INTERVENTIONS}

The Happy House and the Home Build are examples of vernacular architecture, which has been defined and described various ways [3]. For purposes of this paper, we will consider vernacular architecture to be an evolving- local- indigenous- rural- ethnic style of building that may or may not reflect professional design principles. Clay and stone structures, the mud hut, dung and hay dwellings, the banda, the igloo, the toda hut are but a few examples. The HHF Happy House and the NCMH Home Build are also in the category of this view of vernacular architecture. The $10 \mathrm{WASH}+\mathrm{E}$ interventions described in this paper were developed in the S-Lab or adapted by the from existing appropriate technologies and incorporated into the WASH+E package based on their applicability in most rural communities, their efficacy, their cost, their use of local materials and the simplicity of the design. The interventions include:

1. The GSAP Microflush toilet

2. Rainwater harvesting

3. A potable water purification system

4. A Domestic Hot Water (DHW) system

5. A shower

6. A grey water processing system

7. A male urinal

8. A garden utilizing urine and processed grey water for fertilization and irrigation

9. A simple electrical system supplying power for lighting and phone charging

10. A solar cooker

Each of the interventions has component options that impact the cost and a cost model was developed to document donor and recipient contributions for each of these options. Highlighted in the subsections that follow are each of the interventions.

\subsection{The GSAP Microflush toilet}

The GSAP Microflush toilet has been described in recent papers [1]. It was developed under a Grand Challenges Exploration Award from the Bill \& Melinda Gates Foundation, tested early in in field prototypes in Ghana and designed in the S-Lab to be locally fabricated with locally sourced materials. It is an off-grid, sustainable, environmentally friendly, low cost, odor- and fly-free toilet that reuses the small amount ( 1 cup) of greywater from a user's hand wash to isolate waste from space and flush the toilet. A user's flush of waste directly falls into a filter-digester where the solids and liquids are rapidly separated. The solids are composted in an aerobic process enhanced by a macro-organism (e-fetida), a common earthworm. The small filtrate volume is processed naturally in a soak hole - a micro version of a rural leaching field in the US. There is no dislodging of sludge or transportation to a waste processing plant. Every 2 years, the rear cover is removed and an organically rich compost is harvested for use in agriculture.

For the Happy House implementation, a rubble superstructure with a wall common to the house structure makes for a lower cost implementation - less than \$200 versus the average cost of $\$ 300$ with more traditional local materials. There are currently trained toilet MAKERs in 18 countries around the world. Photos of a few examples of the GSAP Microflush toilet are shown in Fig. 1. 

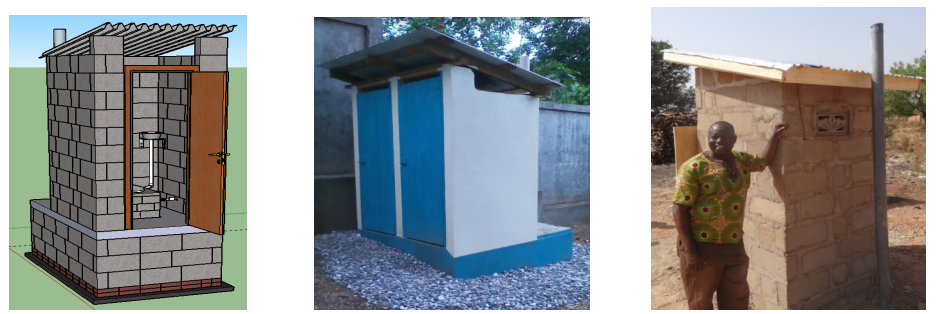

Figure 1: The GSAP Microflush toilet (sketch left); 2-stall version in Haiti (center); household version in Ghana (right).

\subsection{Rainwater harvesting}

Rainwater harvesting requires selection of 3 subsystems: collection, pre-filtering, storage and water release. Our design tool is incorporated in the aforementioned cost model and allows for the conjunction of component options for these functions to effect a final system. The functions and some of the options are shown in Fig. 2.

It is interesting to note that effective gutters can be made from garbage; indeed, repurposed water bottles can be concatenated with a simple concrete too mold to build a gutter section. An example is shown in Fig. 3.

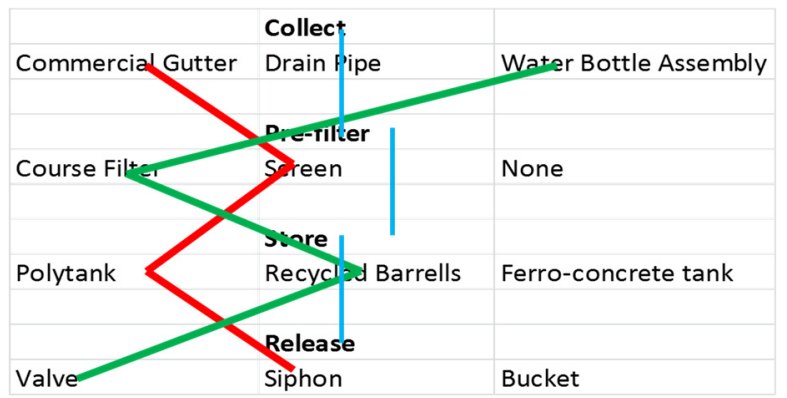

Figure 2: The four functions of rainwater harvesting shown in the vertical bars: collection, pre-filtering, storage and water release. The concatenated connections define two of many options.

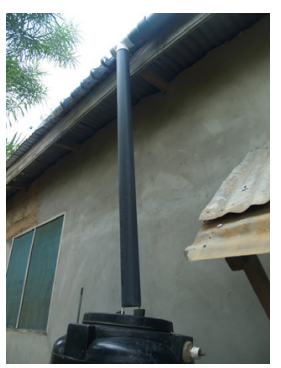

Figure 3: An installation in Ghana showing the use of concatenated water bottles as gutters (upper left in the photo). 


\subsection{A potable water purification system}

Water purification in the WASH+E system is accomplished with a combination of slow sand filtering (SSF) and SODIS. The effectiveness of the latter has been modeled, measured and reported [4]. In all of the WASH+E interventions the emphasis is on effectiveness and cost. As effective as a system might be, if it is not accessible to a family living at the bottom quintile of the household income spectrum, where that income might be less than $\$ 2$ per day, the potential for the intervention will not be realized.

There are SSF designs that involve the use of a 2-part steel mold that is used to fabricate a standing cement filter; these are typically involve costs of $\$ 60$ or more. Unless a charitable organization subsidizes purchase (an unstainable solution) it is out of reach for a poor household. The WASH+E version is a 3-stage modular design that uses 3 repurposed connected common 5-6-gallon plastic buckets. The fabrication uses $1 / 2$ " PVC pipe. Two versions (with slightly different components), one used in Haiti and the other in Ghana are shown in Fig. 4.

\subsection{A DHW system}

The S-lab's work on a Domestic Hot Water system was driven by the possibility of helping to offset some of the fuel (wood or LPG) used to heat water for cooking (and/or bathing). The lab began its work on this intervention by responding to an InnoCentive Challenge [5] by the propane industry to develop a system that repurposes old propane tanks of which there are millions in SSA. Our design, while it didn't win the challenge, was given high marks: "The solution is suitable and has the tendency to permanently remove the substandard cylinders and if adopted has strong environmental and social benefits." Quoting from the S-Lab proposal, "The amount of biomass fuel required to bring $41 \mathrm{lbs}$ (tank capacity) of water from ambient to the temperature achievable in 1 day in the open system is 2600 BTU. The BTU content of $1 \mathrm{~m}^{3}$ of $25 \% \mathrm{MC}$ wood is $\sim 3.4 \times 106 \mathrm{BTU}$. The average efficiency of wood burning cookers is $\sim 20 \%$. If 100,000 households adopted the proposed Repurposed Tank Domestic Hot Water System (RTDHW) to preheat cooking water to $65^{\circ} \mathrm{C}$, savings would be
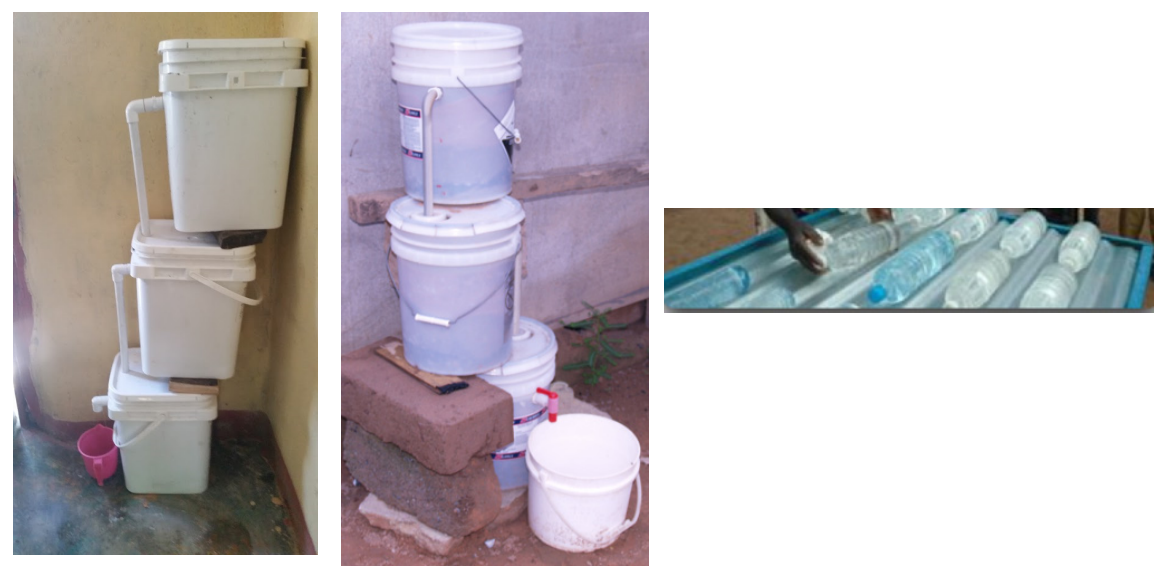

Figure 4: To prototype SSF models, the one on the left from Haiti and the one on the right from Ghana. SODIS with water bottles on roofing is shown above. 
$380 \mathrm{~m}^{3}$ of tree wood equivalent per day. At 4 trees $/ \mathrm{m}^{3}$ and 100 trees per acre, the annual biomass avoidance is 555,000 trees per year or 5550 acres per year saved! Add to this the associated health toll avoidance, atmospheric carbon emissions avoidance (not only from burning biomass but from transporting it from harvest to market), biomass harvesting labor or purchase costs to households and the benefits are staggering. Extend to other West African countries or even more SSA countries and this re-use effort can make a significant and measurable difference on multiple levels." It was the propane industry that offered the challenge. Our solution involved a material cost (including a purchase of the discarded tank) of $\$ 22.50$ per unit.

The tanks would be emptied, stripped of their valves, wire brushed to remove rust, coated with a rust inhibiting primer and then painted black (a non-selective paint is all that is required). The prepared tank could be installed in a simple bread box hinged to allow manual opening at sunrise and closing at sundown. The tank rests on a reflective insulated base. The top of the tank is fitted with a funnel (for filling with water) and a siphoning tube for extraction of hot water. These can be simultaneously fitted or intermittently placed for filling at the beginning of a day and use at the end of the day. The siphoning tube/pipe is made to extend to the bottom of the tank. The "bread box" can be an inverted plastic bucket lined with foiled insulation facing inward and the aperture made by the cut can be left open or glazed with clear plastic (for slightly improved performance. The entire system is shown in the sketches in Fig. 5 in front and side views.

It should be noted that a simpler less expensive version with the tank resting on a foiled (and insulated) surface such as that shown in Fig. 6 is also effective, though the performance is a bit below that of the system depicted in Fig. 5 .

In between these two extremes, are options that have incremental cost and performance implications. For example, the simple system depicted in Fig. 6 can be covered with an insulated bucket at the end of the day to decrease standby losses.

When used for food preparation, the hot water is taken directly, when used for bathing, a mixing valve for blending hot and cold water (can also be from a repurposed tank) can be used. Appendices for a low-flow shower valve (and with subsequent capture of the bathing water useful for floor washing and such) are quite simple to include. Assuming a 1:4 mix, 3-4 warm showers can be had.

How does the system perform? A simple model representing the physical dynamics was developed and calibrated to a test run of the basic open system. The self-documented model, which accounts for solar insolation rates, conductive and radiative losses is shown in Fig. 7. The test run shown in Fig. 8 was begun at noon and run for 20 hours so effectively it is for half a day of sunshine. A simulation for nearly the same conditions is shown in Fig. 9 with more or less similar results.
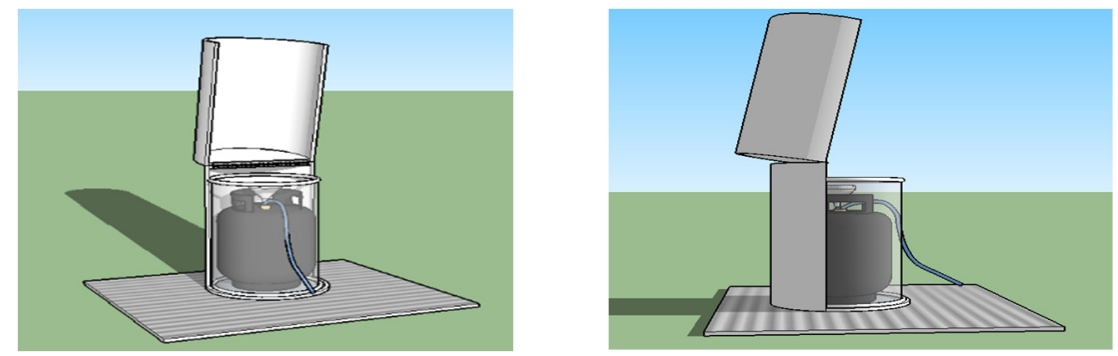

Figure 5: Proposed repurposed LPG tank: solar DHW system. 


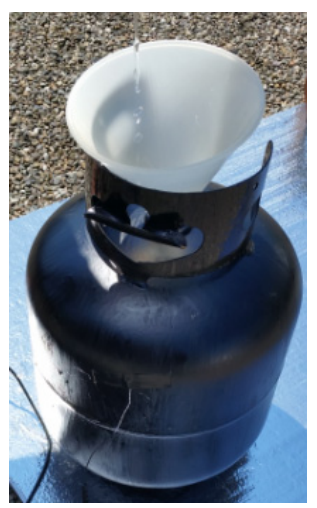

Figure 6: Simple uninsulated open version of the repurposed LPG tank as a solar DHW system.

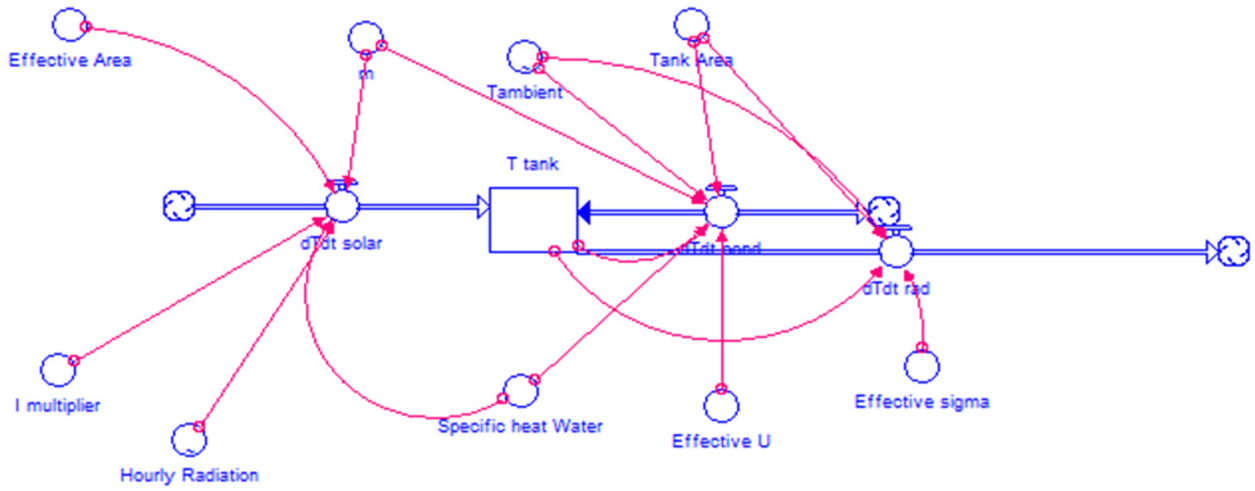

Figure 7: Dynamic model of RTDHW system performance.

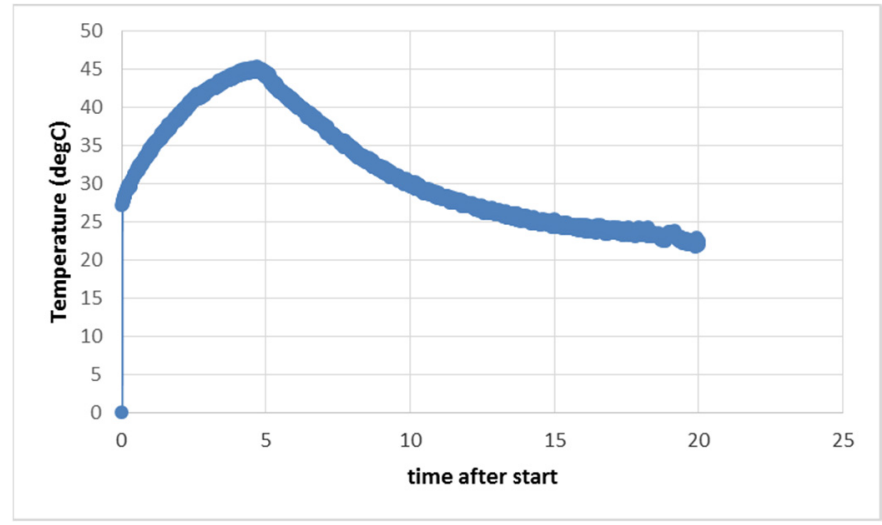

Figure 8: A half day set of measurements of tank temperature in ${ }^{\circ} \mathrm{C}$. 


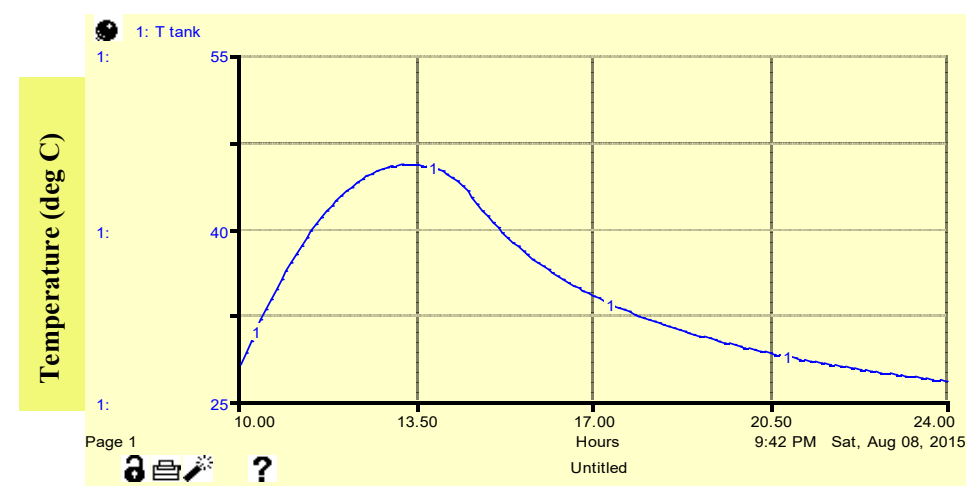

Figure 9: A simulation of half day of clear day sunshine in otherwise similar conditions as the test run.

Once calibrated with the test run in our local conditions, the model is used to simulate results in other regions where solar insolation rates and ambient temperatures are different. A simulation of the simple open system for typical conditions in Ghana, where GSAP's Center is located, is shown in Fig. 10.

Closing the system after sunset, e.g. with an upside down interior insulated bucket, maintains sufficiently high temperatures well into the evening.

While the repurposed propane tank DHW system can be used in regions where the tanks are readily available, a black covered bucket can also be used. Alternatively, a simple camp water bag also performs well as the data in Fig. 11 shows.

The price of a camp water bag is $\sim \$ 12$ but is not available in many village markets around the world. The S-Lab is working on a locally sourced - locally made soft DHW bag perhaps using repurposed materials.

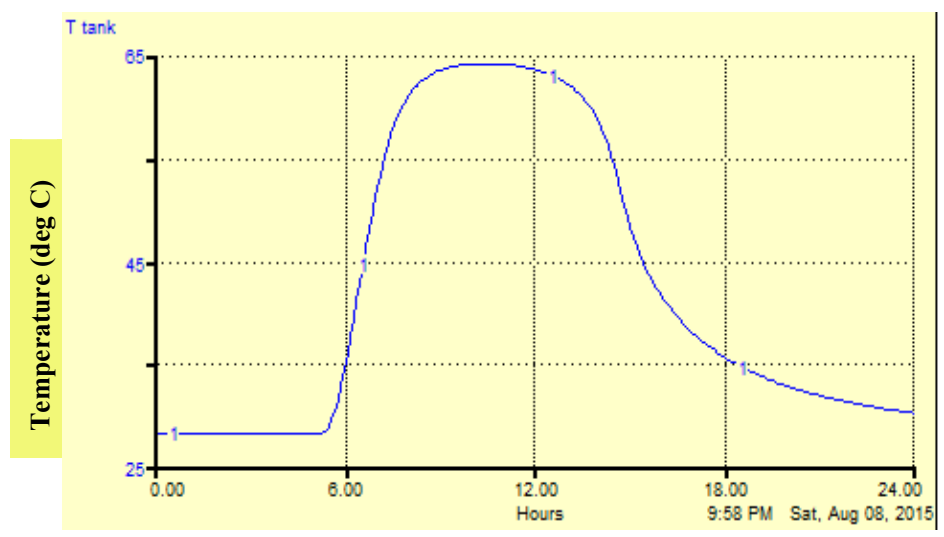

Figure 10: A simulation for conditions in Ghana with an open system. Peak temperatures even without glazing approach $65^{\circ} \mathrm{C}$. 

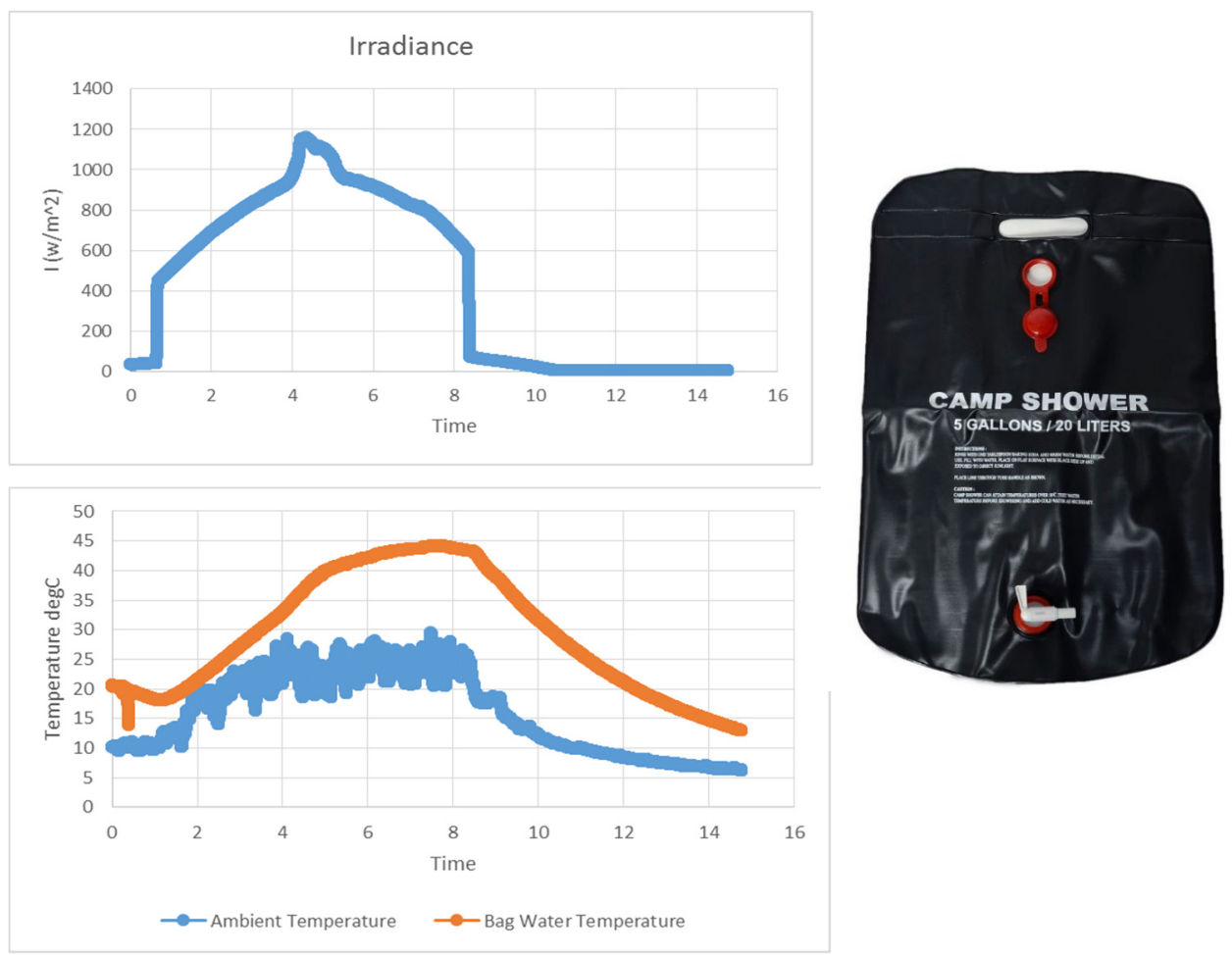

Figure 11: Shown in the lower graph are ambient temperature (blue) and bag water temperature (red), in ${ }^{\circ} \mathrm{C}$, resulting from solar irradiance shown in upper graph for the camp shower bag shown above. Data was taken in April 2016 in Rhode Island USA.

\subsection{A shower}

There is not much to say about this intervention save for the fact that it is extremely low cost if it uses a common wall with the household structure and/or one with the GSAP Microflush toilet, a feature for which we have modeled with several options. In one installation, the DHW bag is used to dispense warm shower water though most of the communities in which we work, showers are taken with ambient temperature water and are found to be refreshing with same. In Ghana, many older people like to bathe with warm water before retiring at night and the combination of a shower and DHW water bag is a nice fit to this custom. The shower can be fitted on the open sides with a simple curtain supported with a bent PVC pipe making a low cast system. The major expense is in the platform, which is made with mesh reinforced concrete pitched to a drain pipe.

\subsection{A grey water processing system}

The drain pipe is led to the grey water system, which consists of 2 recycled jerry cans shown in the centre segment of Fig. 12. The lab prototype is shown in the right segment. Grey water is led to the bottom of the first tank with a recycled bicycle tube 'sock' and the upper level 
of the tank is led to the bottom of the second tank with a pipe and elbow fitting. The rightmost segment of Fig. 12 shows the turbidity with time after the first tank is loaded with grey water and additions are made of grey water with 200 NTU turbidity each day at noon. The water that exits results in a factor of 3 turbidity reduction in the top of the second tank. While holding times of a few days are desirable, even a 1-2-day retention will produce acceptable turbidity values. The use of tanks versus fixed concrete structures makes periodic cleaning of the sediments very easy. Tank volumes are driven by the average number of showers taken per week.

\subsection{Male urinal}

Observers have noted that, even when a public toilet has a urinal inside, men in West Africa often prefer to urinate against a wall outside rather than use the facility in the block. Urine, which is high in nitrogen, moderate in phosphorus with some potassium and other elements, has been found to be an effective fertilizer for plants and its use as such has been fostered in communities in SSA [6]. While commercial enterprises capturing, holding, collecting, shipping and selling urine have been lacking, its use in household gardens and such has the potential to avoid costly and environmentally threatening commercial fertilizers. One of the authors (SM) has observed extension services successfully demonstrating and promoting this use in Rwanda. The S-Lab has designed a low-cost, odor-free urinal for use at rural Households as part of its WASH+E package. Required is a used jerry can, funnel or inverted and scalloped used gallon jug for the storage and user interface. A snipped condom can be stretched over the gallon jug screw cap area; this makes an effective differential valve for admitting urine and closing after the liquid has passed through preventing odors from sitting urine having odor-producing bacteria. A sketch and photo are shown in Fig. 13. While it is possible to use a UDDT (urine diverting fixture) in the Microflush toilet, we do not recommend this change; the little urine going into the filter-digester can have two effects. Urine can enhance composting but through a two-stage process can disinfect a mass interfering with the macro-organism enhanced aerobic process of the digester. Fortunately, the two sequential steps are not realized in the toilet system and the small amount of urine can serve to accelerate the composting process [7].
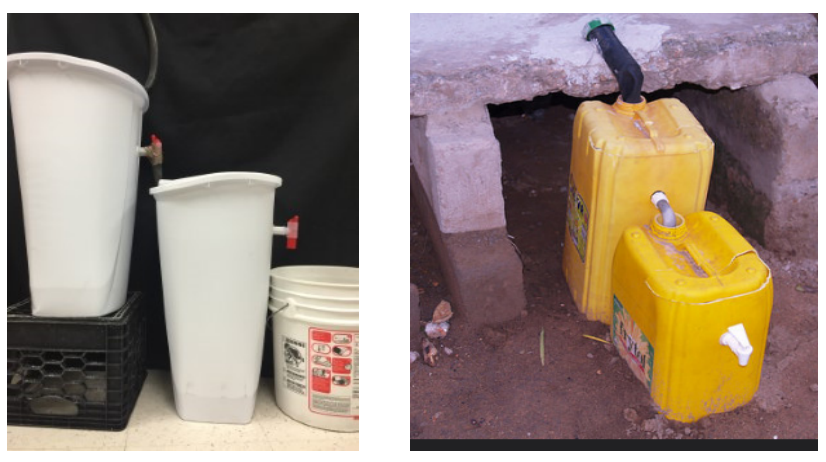

\begin{tabular}{|c|c|c|}
\hline $\begin{array}{l}\text { Day (added } \\
\text { about noon } \\
\text { each day) }\end{array}$ & $\begin{array}{l}\text { Turbidity } \\
\text { Top of } \\
\text { Tank 1 } \\
\text { (NTU) }\end{array}$ & $\begin{array}{l}\text { Turbidity } \\
\text { Top of } \\
\text { Tank 2 } \\
\text { (NTU) }\end{array}$ \\
\hline 0 & 201.6 & \\
\hline 1 & 62.5 & \\
\hline 2 & 45.7 & \\
\hline 3 & 30.6 & \\
\hline 4 & 25.4 & \\
\hline 5 & 22.8 & \\
\hline 6 & 20.9 & \\
\hline 7 & 20.4 & 6.2 \\
\hline 8 & 20.1 & 5.9 \\
\hline 9 & 20.3 & 5.7 \\
\hline
\end{tabular}

Figure 12: Simple dual tank grey water processing; lab prototype (left image); field installation in Ghana (centre image); top of tank turbidities (right image). 

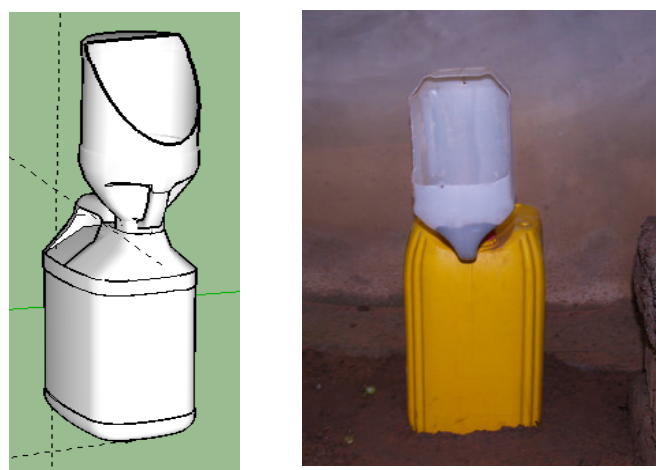

Figure 13: Sketch (left) and field prototype (right) of a low-cost male urinal.

\subsection{A garden utilizing urine and processed grey water for fertilization and irrigation}

Small household gardens promise an improvement to food security. Yet the value of such gardens in rural developing communities has been somewhat controversial [8]. Lack of realization of local conditions is one of the reasons cited for shortfalls in expectations. Lack of water and knowledge are also a problem in many communities. Nevertheless, while a small household garden should not be seen as a steady source of income or food, when appropriate consideration is given to local conditions, it nevertheless offers a partial strategy for improving food security [9] especially in providing nutrient rich vegetables and it may be more sustainable than government subsidies and goodwill charitable interventions [10].

The layout, size and planting details of the garden in the WASH+E program will depend on local factors and preferences. Collected urine mixed with 15-20 parts processed grey water can be applied for irrigation and fertilization; the latter function can be enhanced with compost periodically harvested from the toilet and reuse of some cooking water. Volumes of such water-urine can range from 20-40 liters per day in a typical household. Evaporationtranspiration rates for the local community need to be estimated to determine the area of garden that can be supported with such moisture. Simple measures, such as visqueen barriers, plant cups made with water bottle tops and targeted irrigation can help reduce the water requirements and allow for a larger garden.

\subsection{A simple electrical system supplying power for lighting and phone charging}

Early efforts to supply power for lighting and phone charging focused on systems such as the one shown in Fig. 14 (left frame). This system was configured for the HHF Happy House which consists of 3 rooms (a living space and 2 bedrooms). It consists of three $5 \mathrm{v}$ LED bulbs, a 15-mAH LiPo battery and a 14-watt solar charger (not shown in this figure). The performance of this system is shown in the right frame of the figure.

The configured system costs $\sim \$ 55$. The system will run three lights from a fully charged LiPo battery for 40 hours; at 5 hours per day (night), this is clearly overkill for a household in a sunny rural tropical community. We have moved to a more modest and cost-effective system for lighting and cell phone charging that results in a solution that is under $\sim \$ 25$. The S-Lab has also developed a DIY LED bulb using the top area of a small water bottle and 2-3 LEDs. Compared to the commercial fixtures shown in the original configuration (Fig. 14), which are $\$ 3.28$ each, the DIY model is just $\$ 0.10$ in parts. 

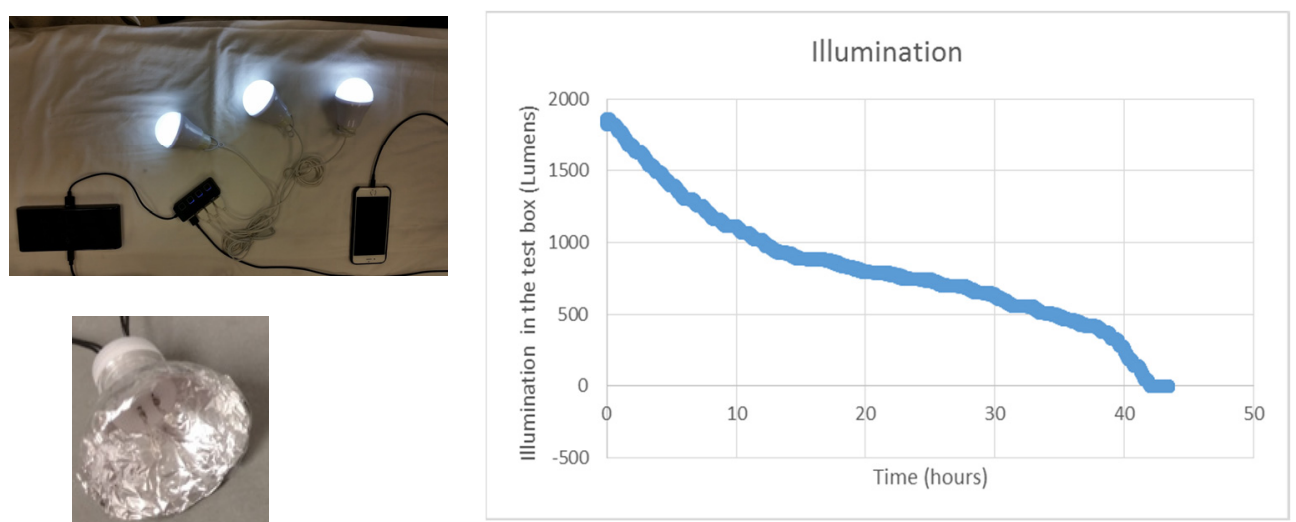

Figure 14: Components of the original prototype (top left) showing the LiPo battery, USB switch, lights and phone charging. Illumination (right) in a light box for the configured prototype. See text. Water bottle fixture option (lower left).

\subsection{A solar cooker}

The final component of the WASH+E system is a solar cooker or a solar oven, both can be made locally. Solar International [11] offers several low-cost DIY approaches. One such example is the solar cooker shown in Fig. 15, which involves simple glue (starch from Cassava can also work), aluminum foil and repurposed cardboard. The cost of purchased materials is $\sim \$ 2$. While solar cookers haven't gained widespread adoption in the developing world, households that have used this simple technology save wood, charcoal or propane (the more traditional fuels for cooking) and the negative environmental and health impacts associated with their use.

\section{SYSTEM COSTS}

The S-Lab has developed a model for costing each of the interventions comprising the WASH+E system allowing for different material options for each subsystem. A partial image of the interface is shown in Fig. 16. It features pull downs for each optional subsystem component, manual over-rides for unique local materials, breakout of donor- and recipientsupplied items and a summary (not shown) of the entire project costs (donor and recipient supplied materials and labor).
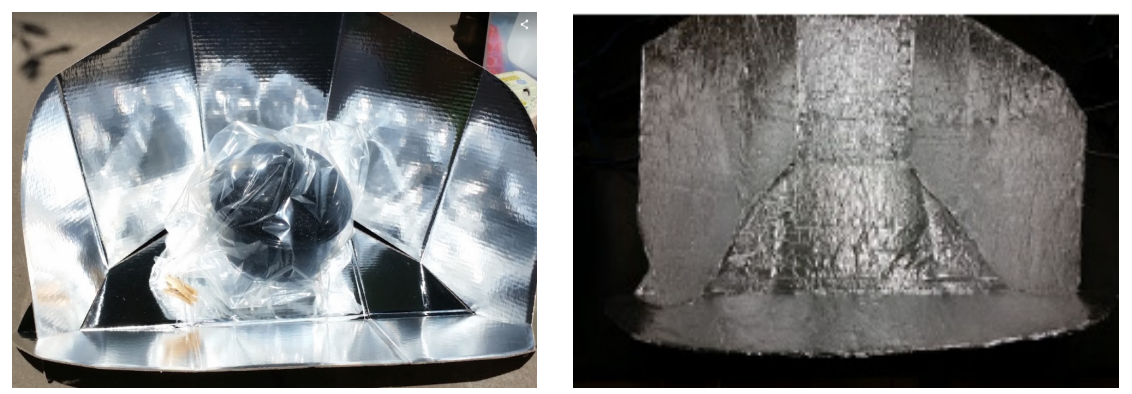

Figure 15: A typical SCI kit solar cooker (left); homemade version (right). 


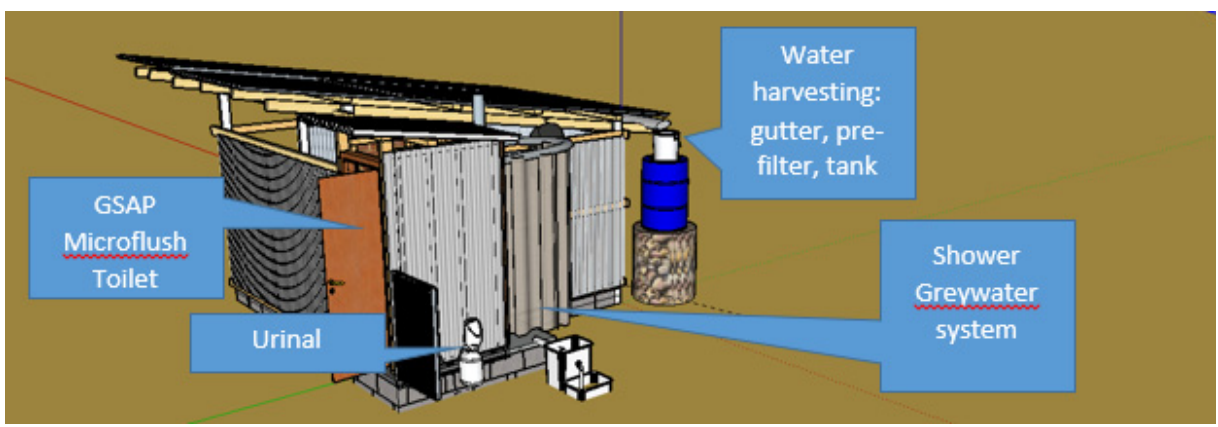

Figure 16: Sketch of the Home Build in Nicaragua showing a few of the WASH+E interventions. Not shown are the DHW, Potable Water SSF, Lighting, Solar Cooker and Garden interventions. The toilet uses a common wall with the Home Build saving some material costs.

The toilet is the most costly of the interventions. It can range from $\$ 300$ to $\$ 190$ depending on how it is situated and the type of superstructure materials being applied. When a segment of the wall of the house is used as a common wall with the toilet, material costs are lower. Of the remaining 9 interventions, the water storage tank and the energy lighting-charging system are next highest in cost. The entire package of 10 interventions has a cost of $\sim \$ 300$ for the standard choice of options.

\section{GOING TO SCALE, COOPERATIVE POTENTIAL AND FUTURE EFFORTS}

Several of the interventions as they are planned for the Home Build in Nicaragua, a basic shed roof structure costing $\sim \$ 450$ in materials, are shown in Fig. 17. While $\$ 300$ will bring the Home Build cost to $\$ 750$.

Detailed social value analyses are underway in the S-Lab; early results point to an outstanding SROI for the incremental household investment of $\$ 300$.

Several models for deployment are being considered. GSAPs toilet MAKER model can be augmented to include the other nine interventions. However, while the toilet requires the skill of a trained artisan (the MAKER), the WASH+E program has a few DIY elements as well as components that can be efficiently assembled with practice using low skilled labor. Extension services, community and cooperative enterprises especially in tropical areas around the world abound [12]. Beginning in 1985100 poor women in Bogota, Columbia, launched a cooperative utilizing rooftops to grow vegetables for supermarkets, using unmarketable products for their own consumption [8]. GSAP believes the co-op, perhaps mediated by its toilet MAKERs around the world can be an effective vehicle for bringing the WASH+E interventions to vernacular housing in peri-urban and rural communities. GSAP's mission to empower women would emphasize women co-ops. Individuals in the cooperative could develop a particular skill, e.g. fabricating water bottle gutters could be the specialization of one woman, while building the modular SSF tanks could be that of another, etc. The homes of the members would be outfitted with the interventions and become models for households in the community. Co-op labors would be rewarded with sales in the community. Some of GSAPs MAKERs around the world are working in cooperatives to deploy Microflsuh toilets in their communities. An excellent example is the women of Procasha, a building cooperative of women, who are working together as GSAP toilet 


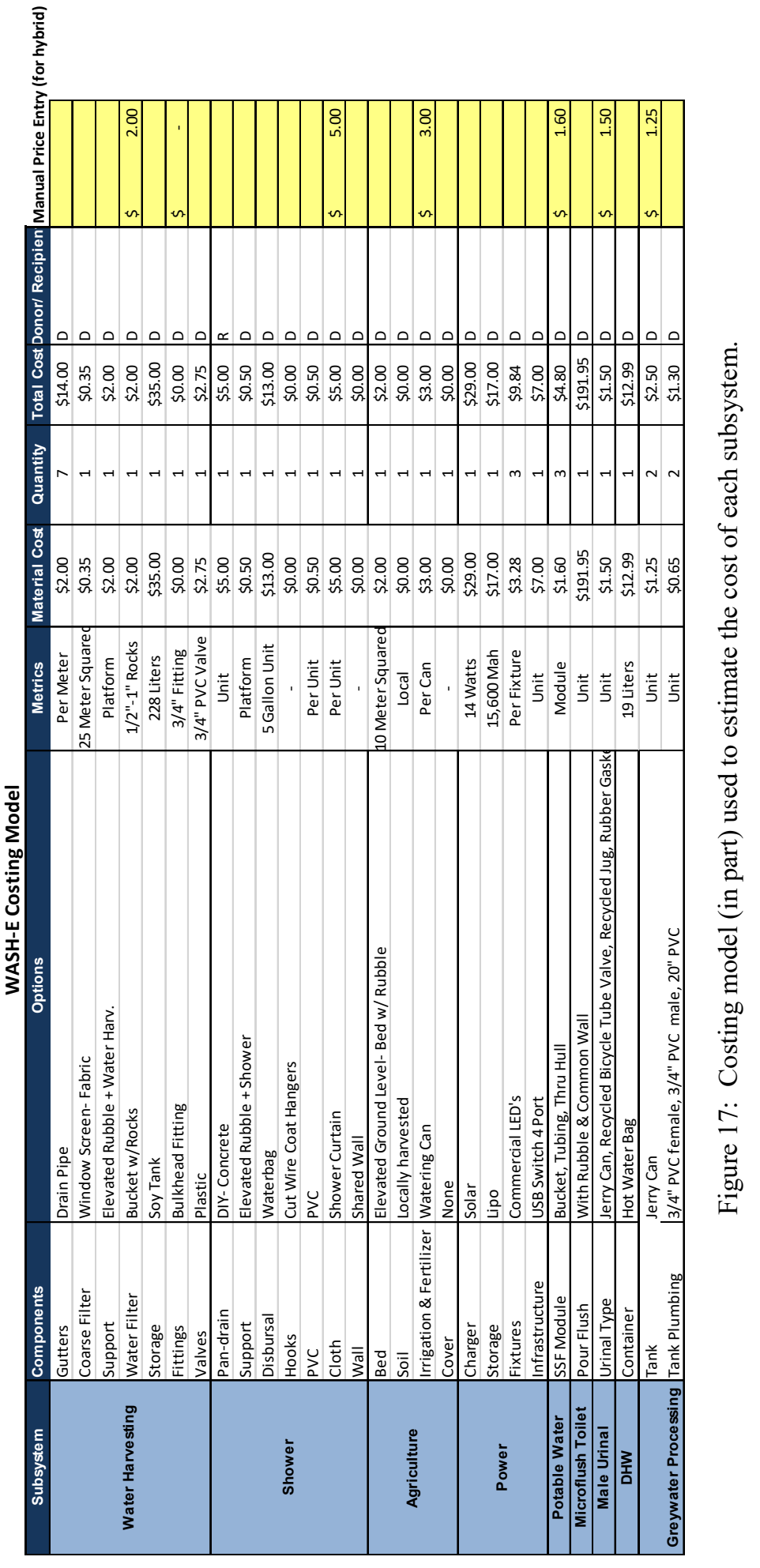


MAKERs. Another is the Maasai in southern Kenya, who are doing the same; they are also fabricating some of the material supplies for the toilets and hence realizing a larger part of the toilet sale as proceeds. The purchasing power, skill-efficiency and community penetration of the cooperative are factors that suggest this as a potentially powerful approach to bringing the WASH+E program to scale. Our hope is that this will contribute in part to a realization of several of the UN's Sustainable Development Goals [13].

\section{REFERENCES}

[1] Mecca, S., Davis, H. \& Davis, A., The Microflush/Biofil System: Results to Date of Prototype Installations in Ghana, Faecal Sludge Management FSM2 Conference, Durban 2012.

[2] Mecca, S., Davis, H. \& Davis, A., Application of GSAP Microflush toilets: A sustainable development approach to rural and peri-urban sanitation. WIT Transactions Ecology and the Environment, 175, 2013.

[3] Noble, A.G., Traditional Buildings: A Global Survey of Structural Forms and Cultural Functions, I.B. Tauris: London, pp. 1-17, 2007.

[4] Mecca, S., Pellock, B. \& Bretz, R., Pathogen removal options emphasizing SOLDIS for the filtrate of a GSAP Microflush toilet. WIT Transactions on Ecology and the Environment, 178, 2013.

[5] Mecca, S., GSAP \& S-Lab, Ideas to Impact: Recycling Liquid Petroleum Gas Cylinders Across Sub-Saharan Africa, Repurposing propane tanks for solar domestic hot water, InnoCentive Challenge \#9933755, 2015.

[6] Grunbaum, M., Gee Whiz: Human Urine Is Shown to Be an Effective Agricultural Fertilizer, Scientific American, a division of Nature America, Inc., 23 Jul., 2010.

[7] Shrestha, D., Srivastava, A., Man Shakya, S., Khadka, J. \& Acharya, B.S., Use of compost supplemented human urine in sweet pepper (Capsicum annuum L.) production. Scientia Horticulturae, 153(4), pp. 8-12, April 2013.

[8] Marsh, R., Building on traditional gardening to improve household food security, FNA/ANA 22, FAO.org, 1998.

[9] Midmore, D.J., Niñez, V. \& Venkataraman, R., Household gardening projects in Asia: Past experience and future directions. AVRDC Technical Bulletin No. 19, Shanhua, Taiwan Province of China, AVRDC, 1991.

[10] Niñez, V.K., Household gardens: Theoretical considerations on an old survival strategy, Lima, Peru, International Potato Center, 1984.

[11] Solar Cookers International, Solar Cookers, 10th ed., 2004.

[12] Kumar, B.M. \& Nair, P.K.R., Tropical Homegardens: A Time-Tested Example of Sustainable Agroforestry, Springer Science \& Business Media, 379 pp., 21 Apr. 2007.

[13] United Nations Sustainable Development Goals, http://www.un.org/ sustainabledevelopment/sustainable-development-goals. Accessed on: 15 Sep. 2015. 